\title{
Impact of Wind Profiler Data Assimilation on Wind Field Assessment over Coastal Areas
}

\author{
Soon-Young Park, Hwa Woon Lee*, Soon-Hwan Lee ${ }^{1)}$ and Dong-Hyeok Kim \\ Division of Earth Environment System, Pusan National University, Busan, Korea \\ ${ }^{1)}$ The Institute of Environmental Studies, Pusan National University, Busan, Korea
}

*Corresponding author. Tel: +82-51-510-2291, E-mail: hwlee@pusan.ac.kr

\begin{abstract}
Precise analysis of local winds for the prediction of atmospheric phenomena in the planetary boundary layer is extremely important. In this study, wind profiler data with fine time resolution and density in the lower troposphere were used to improve the performance of a numerical atmospheric model of a complex coastal area. Three-dimensional variational data assimilation (3DVAR) was used to assimilate profiler data. Two experiments were conducted to determine the effects of the profiler data on model results. First, we performed an observing system experiment. Second, we implemented a sensitivity test of data assimilation intervals to extend the advantages of the profiler to data assimilation. The lowest errors were observed when using both radio sonde and profiler data to interpret vertical and surface observation data. The sensitivity to the assimilation interval differed according to the synoptic conditions when the focus was on the surface results. The sensitivity to the weak synoptic effect was much larger than to the strong synoptic effect. The hourly-assimilated case showed the lowest root mean square error (RMSE, $1.62 \mathrm{~m} / \mathrm{s}$ ) and highest index of agreement (IOA, 0.82) under weak synoptic conditions, whereas the statistics in the 1, 3, and 6 hourly-assimilated cases were similar under strong synoptic conditions. This indicates that the profiler data better represent complex local circulation in the model with high time and vertical resolution, particularly when the synoptic effect is weak.
\end{abstract}

Key words: Three-dimensional variational data assimilation, Wind profiler, Planetary boundary layer

\section{INTRODUCTION}

Numerical models are widely used to understand and forecast atmospheric phenomena. They have also been applied in studies of the scale of the planetary boundary layer (PBL), which has a direct effect on human activity. These studies are performed primarily in the field of applied meteorology. Typically, the results of atmospheric models are used as input data for air quality models. Recently, these data were used to evaluate and forecast wind power energy (Kim et al., 2006). Current atmospheric models have limitations for examining the characteristics of the PBL because they calculate phenomena by parameterization. Local wind develops easily due to surface effects caused by complex coastlines and mountains of areas such as the Korean Peninsula (Lee et al., 2004). To overcome this limitation, asynoptic observation data that reflect meso- or micro-scale phenomena are assimilated into numerical models.

To evaluate how the assimilation of atmospheric models and observation data affects air quality predictions, Lee et al. (2007) assimilated dense surface observations into atmospheric models and showed that predictability of the air quality model was enhanced in coastal areas. They concluded that this characteristic depended on the heterogeneity of surface characteristics. Lee et al. (2009a) insisted that observation data should be assimilated into numerical models to estimate local wind resources, and suggested applying different radii of influence and nudjing coefficients according to topography and synoptic conditions. These studies used observation data from a surface automatic weather station (AWS) to assimilate meteorological data on a smaller scale than the synoptic scale. It is important to assimilate vertically dense observation data for analyses below the PBL in three dimensions.

The wind profiler (hereafter referred to as the profiler) is among the vertical observations used in data assimilations to observe flow in the lower atmosphere. The profiler data produced around coastal areas are important for studies of the Korean Peninsula, which has a complex coastline and complicated wind distribution. Profiler data are used to compensate for the absence of vertical observation data over the ocean. The use of a profiler is suitable to better understand atmospheric phenomena over short time scales, because it pro- 
vides excellent time resolution and vertical intervals. Benjamin et al. (2004) explained how the profiler is applied to numerical weather predictions in the USA, and reported that predictability was enhanced. Ishihara et al. (2006) found that the presence of a dense profiler network contributes to weather prediction in Japan. In Korea, the National Institute of Meteorological Research (2003) and the Korean Meteorological Administrator actively use 10 profilers starting from Haenam for weather prediction.

Observing system experiment (OSEs) are used to evaluate the effects of observation data on numerical models that compare existing methods with experimental methods in which new observation data are added or removed. OSEs can be used to estimate the effects of observation data and determine the standards for induction of an observation system (Park et al., 2005). In addition, numerous studies have been carried out to determine the impacts of a range of observation data (Won et al., 2008; Hirschberg et al., 2001; Atlas, 1997).

In this study, three profilers that are located on the southwest coastline of Korea were used for threedimensional variational data assimilation (3DVAR) to precisely simulate the atmospheric flow in the PBL around complex coastal areas. Also, an experiment of data assimilation interval was carried out to investigate the advantages of the time resolution of profiler.

\section{METHODS}

\subsection{Area of Interest and Selected Cases}

The area of interest ranges over South Korea from the Yellow Sea to the South Sea. We examined the effects of profiler data on predicted wind distribution in coastal areas (Fig. 1). The southwestern coastal area is expected to have a complicated wind distribution due to its complex coastline. This area was selected as the area of interest to determine the effects of data assimilation on the atmospheric model for a complex area.

Two continuous days that showed a contrast in synoptic pressure were selected for the numerical simulation (Fig. 2). The weather on June 4 and 5, 2007 was typical for early summer before the arrival of the seasonal northward-propagating rain front. Both days were sunny but showed different distributions of synoptic pressure. The high pressure center was located in South Korea under the effect of the North Pacific high. Because of these synoptic conditions, the wide pressure contour caused the sky to be clear and generated local wind-like land-sea breezes or mountain-valley winds. On June 5, however, the dominant high pressure of June 4 was pushed in the southeastern direction by low pressure located north of the Korean Peninsula. Consequently, the pressure contour line narrowed and a strong synoptic wind developed as a result of the intensified pressure gradient force. The different wind features over the two days were described by Lee $e t$ al. (2009b) through enhanced surface and vertical observations.

\section{2 Data and Experimental Methods}

The numerical model used in this study was the Weather Research and Forecasting (WRF) model v3.0 (Skamarock, 2008), which employs Arakawa-C grid staggering and is comprised of fully compressible and non-hydrostatic equations. The domain area is shown in Fig. 1. The first domain is Northeast Asia centered on the Korean Peninsula, which has a grid resolution of $9 \mathrm{~km}$. The initial and boundary data of Domain 2 were obtained through one-way nesting of Domain 1. The horizontal resolution and grid dimensions of Domain 2 were $3 \mathrm{~km}$ and 250 by 250, respectively, and both domains consisted of 35 vertical layers. The

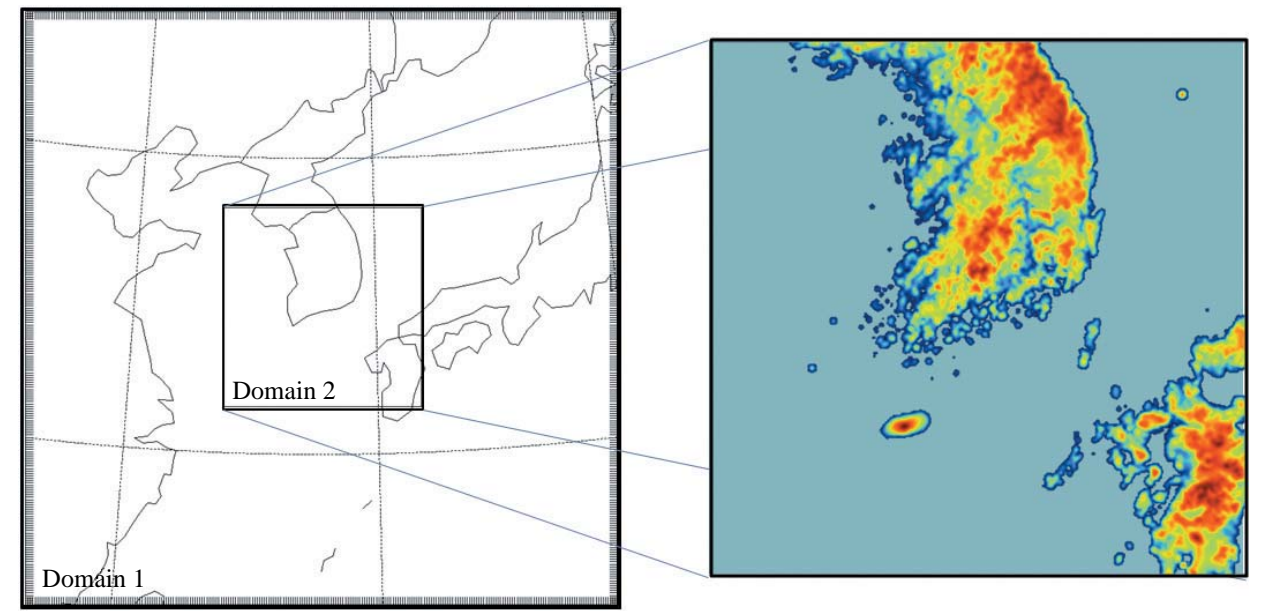

Fig. 1. Map depicting the two horizontal WRF domains. 
09LST June 4

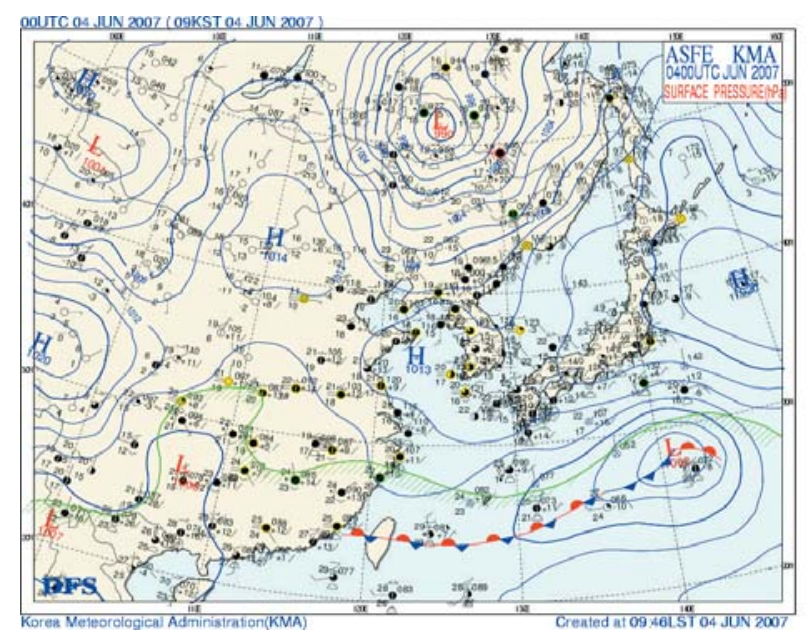

09LST June 5

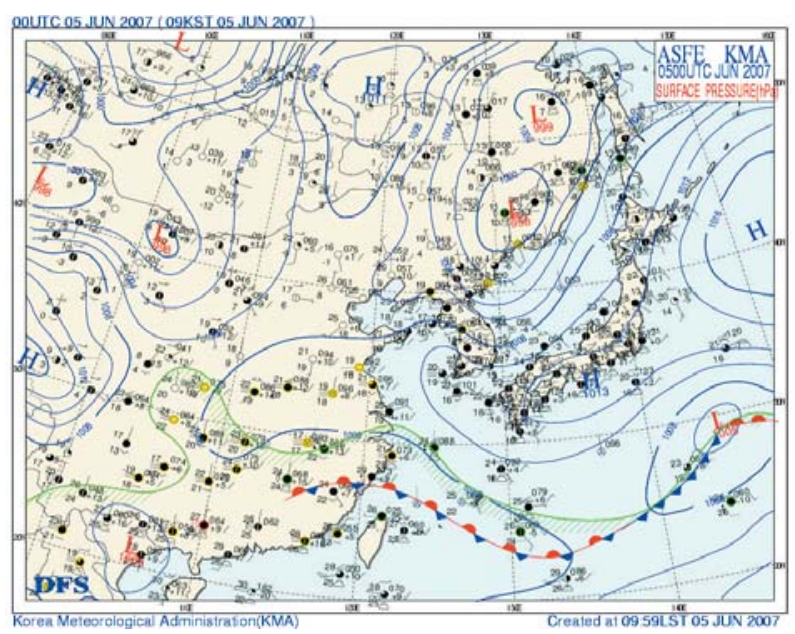

Fig. 2. Surface weather chart on June 4 and June 5, 2007.

Table 1. Configuration of WRF.

\begin{tabular}{lcc}
\hline & Domain 1 & Domain 2 \\
\hline Horizontal grid & $249 \times 249$ & $250 \times 250$ \\
Horizontal resolution & $9 \mathrm{~km}$ & $3 \mathrm{~km}$ \\
Vertical layers & \multicolumn{2}{c}{35} \\
Physical options & WSM5 scheme \\
& Kain-Fritsch scheme \\
& Noah LSM \\
& Yonsei University PBL \\
RRTM Longwave \\
Titial data & Dudhia Shortwave \\
Time period & NCEP FNL data \\
& 00UTC June 3, 2007- \\
\hline
\end{tabular}

NCEP Final Analysis (FNL) data, taken at 6 hour intervals and a resolution of $1^{\circ} \times 1^{\circ}$, were used for the initial and boundary conditions of Domain 1. Table 1 outlines the detailed model configuration.

We used the 3DVAR data assimilation technique, which considers the dynamic balance between variables, employs error statistics of the model and observations, and is more elaborate than interpolation of observations, nudging, and optimal interpolation (OI). The basic goal of any variational data assimilation system is to produce an optimal estimate of true atmospheric state at the time of analysis through the iterative solution of a prescribed cost function(Ide et al., 1997). This method can utilize radar echo and satellite surface radiative data in addition to directly-observed meteorological data (University Corporation for Atmospheric Research, www.meted.ucar.edu; Mike, 2001). The advantage of using the profiler is that the dynamic equation and error covariance between vertical layers

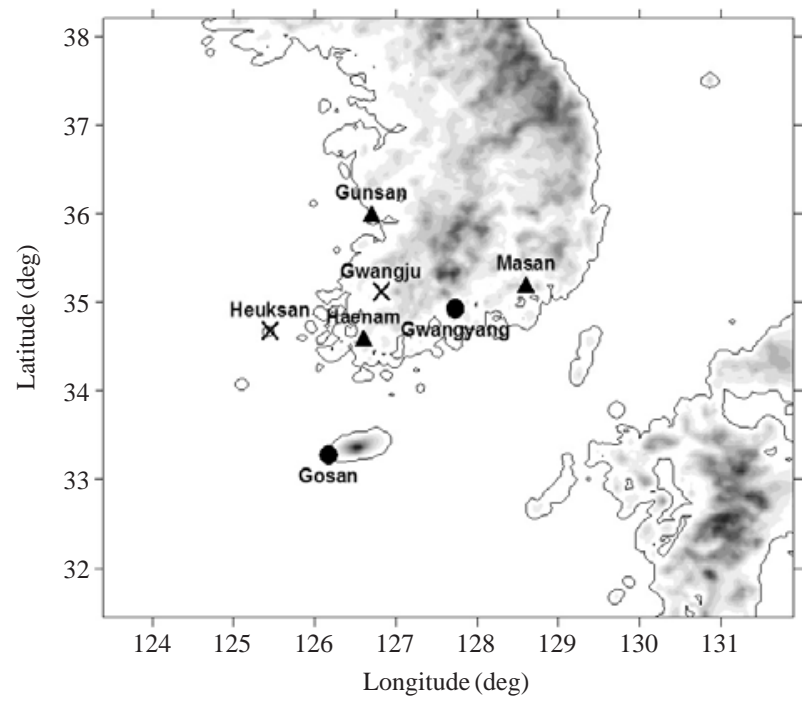

Fig. 3. Location of wind profiler $(\boldsymbol{\Delta})$ and radio sonde $(x)$ sites used in data assimilation. Black $\operatorname{dot}(\bullet)$ indicates radiosonde sites used for comparison with model results.

can be examined vertically. The 3DVAR method for the WRF model follows the procedure explained by Barker et al. (2004).

The observation data were obtained from the profiler, radio sonde (hereafter called sonde), and AWS. The profiler utilizes a type of Doppler radar that can continuously observe vertical wind distribution with high temporal and spatial resolution. Therefore, these data are useful for detecting severe weather that occurs on a small horizontal scale over short time periods. The profiler can also be observed continuously at low cost because of its capability for remote detection. The 
Table 2. Experimental design of OBS-EXP(OBServational EXPeriment) and INT-EXP(INTerval EXPeriment).

\begin{tabular}{llcccc}
\hline & & NO_DA & WP_DA & RS_DA & AL_DA \\
\hline \multirow{2}{*}{ OBS-EXP } & Wind profiler & $\times$ & 0 & $\times$ & 0 \\
& Radio sonde & $\times$ & $\times$ & 0 & 0 \\
\hline & & 1h_DA & 3h_DA & 6h_DA & 12h_DA \\
\hline INT-EXP & Data assimilation interval & 1 hour & 3hour & 6hour & 12 hour \\
\hline
\end{tabular}

Gunsan, Haenam, and Masan profiler sites near the South and Yellow Seas were selected to investigate wind variation over the southwestern coast of Korea (Fig. 3). Fig. 3 shows the sonde sites that were used for data assimilation and for comparisons with experimental results. The sonde data from Gwangyang is not typically reported to the World Meteorological Organization (WMO), and is a special observation (Lee et al., 2009b). The last data set includes AWS data from 33 meteorological observatories around the assimilated profiler and sonde, which were used to confirm the effects of data assimilation.

An experiment to assess the effects of profiler data on the existing system of sonde data assimilation, namely OSE, was conducted. This experiment was called OBS-EXP, and included four cases: no data assimilation, profiler assimilation, sonde assimilation, and the assimilation of both sets (NO_DA, PF_DA, RS_DA, and AL_DA). The WRF-Var cycling mode (National Center for Atmospheric Research, 2008) was applied to OBS-EXP every six hours. The second experiment was a data assimilation interval experiment, INT-EXP, to evaluate the enhancement to model performance that occurs when using a high temporal resolution of 10 minutes. In addition to 6 hour intervals (6h_DA), 1 hour, 3 hour, and 12 hour interval experiments were carried out, called 1h_DA, 3h_DA, and 12h_DA. In INT-EXP, the sonde and profiler data was used and 6h_DA was the same as AL_DA in OBS-EXP. Table 2 lists all configurations.

\section{RESULTS AND DISCUSSION}

\section{1 Horizontal Wind Fields}

Fig. 4 presents the results for OBS-EXP while inspecting changes in horizontal wind at $10 \mathrm{~m}$. A sea breeze developed around all coastal areas of the Korean Peninsula because of the weak synoptic force at 1200 LST on June 4. Due to the sea breeze, the wind speed was greater along the coastal line than inland. At 1500 LST, June 4 (not shown), the sea breeze intensified and penetrated inland. In each case, there was a slight change in wind direction and a considerable change in wind speed. Remarkable differences were observed in the Yellow Sea and the Southern Sea, which showed weak (0-2 ms $\left.\mathrm{ms}^{-1}\right)$ and strong (4-6 ms $\left.{ }^{-1}\right)$ wind speeds, respectively. The atmosphere stabilized at night and weakened the wind speed, but a mountain wind occurred in the mountainous area. The wind speed over the southern sea was decreased by the data assimilations, and the distribution for PF_DA was similar to that for AL_DA. This explains why the results from AL_DA were primarily affected by the profilers at Haenam and Masan adjoining the Southern Sea. During the day of June 5, when the synoptic force was strong, a clockwise wind field appeared at the edge of the North Pacific high pressure region and prevailed over the entire domain. An approaching low pressure region at the northeast of the Korean Peninsula reinforced the pressure gradient force, so that the wind speed was stronger than on June $4\left(4-7 \mathrm{~ms}^{-1}\right)$. Moreover, the differences in wind speed distribution over the sea were much greater than they were inland because the profiler and sonde are located along the seashore.

Fig. 5 shows the results from INT-EXP, which was designed to apply the time resolution of the profiler. Although the difference in wind direction caused by the synoptic effect was similar to the OBS-EXP results, the wind speed distributions were distinct for all cases of INT-EXP. The 1h_DA shows that the wind speed intensified over the southwest region of the Korean Peninsula with enhanced penetration of the sea breeze. The distribution of wind speed over the southern area in NO_DA (Fig. 5) was 4-6 $\mathrm{ms}^{-1}$, which weakened to $3-5 \mathrm{~ms}^{-1}$ for 1h_DA. These results show that the greatest change in wind speed is explained by the frequent use of profiler data. The differences in each case on June 5 were not significant because predominant synoptic forcing had little effect on data assimilation over time.

\subsection{Comparison with the Vertical Observation Data}

Fig. 6 shows a comparison between the OBS-EXP results and the observations at Haenam (a) and Masan (b), which were the profiler observation points for data assimilation, and at Gwangyang (c) where data assimilation was not carried out. Because the observed values at the profiler sites were provided excellent vertical 
12LST June 4

(a)

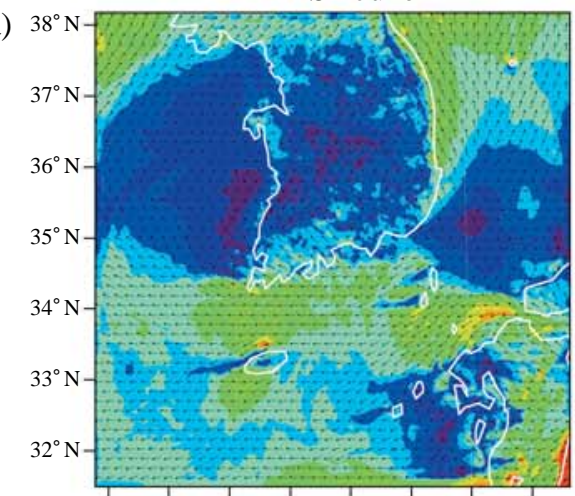

(b)

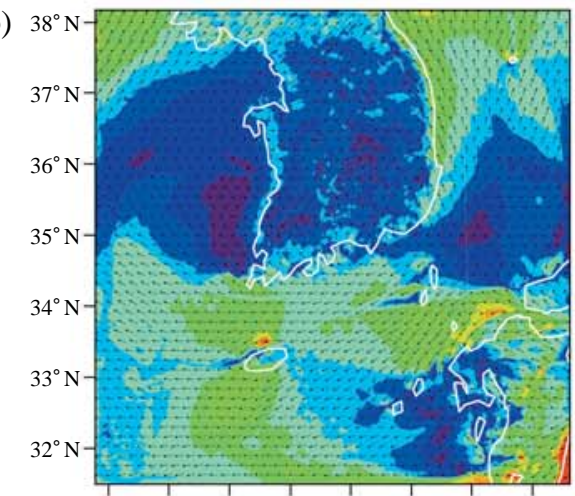

(c) $38^{\circ} \mathrm{N}$

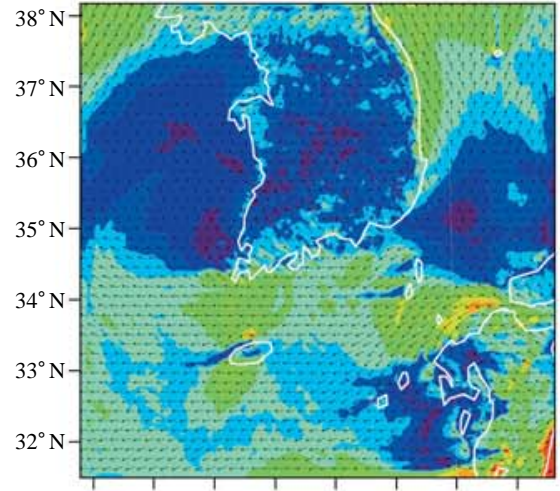

(d)

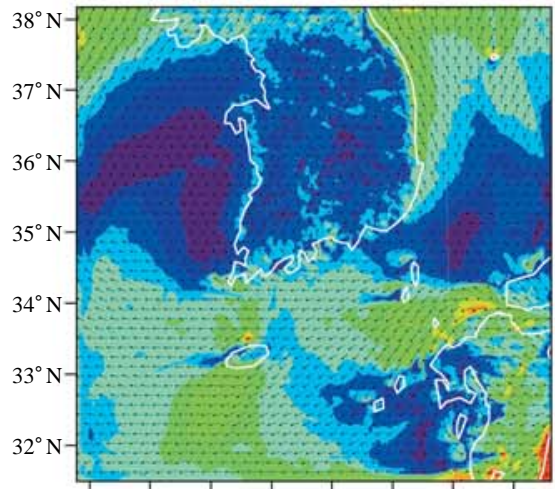

$124^{\circ} \mathrm{E} 125^{\circ} \mathrm{E} 126^{\circ} \mathrm{E} 127^{\circ} \mathrm{E} 128^{\circ} \mathrm{E} 129^{\circ} \mathrm{E} 130^{\circ} \mathrm{E} 131^{\circ} \mathrm{E}$

Wind speed $(\mathrm{m} / \mathrm{s})$

$\begin{array}{lllllllllll}0 & 1 & 2 & 3 & 4 & 5 & 6 & 7 & 8 & 9 & 10\end{array}$
OOLST June 5
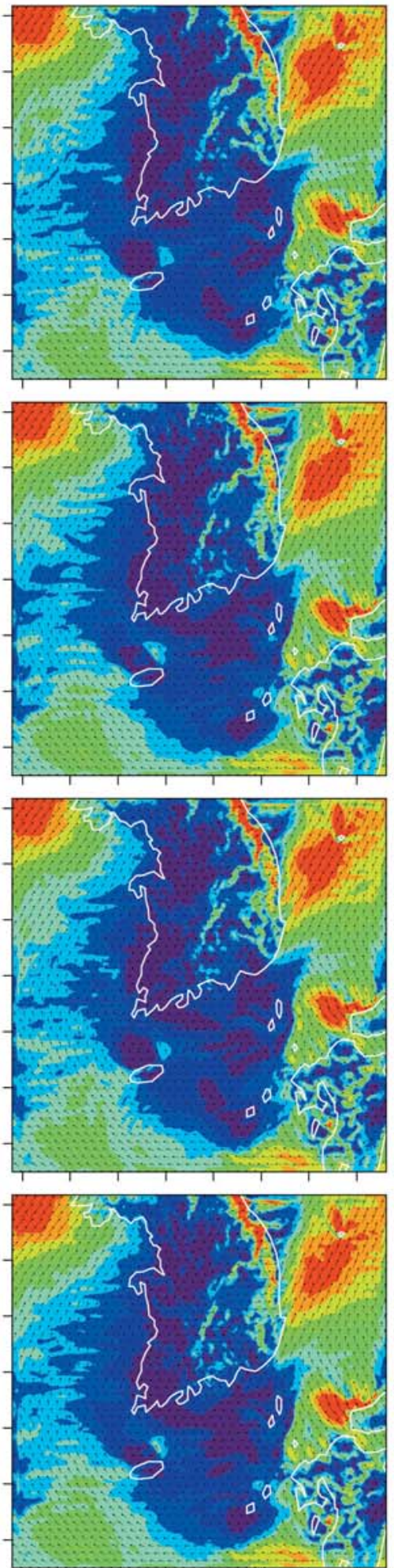

$124^{\circ} \mathrm{E} 125^{\circ} \mathrm{E} 126^{\circ} \mathrm{E} 127^{\circ} \mathrm{E} 128^{\circ} \mathrm{E} 129^{\circ} \mathrm{E} 130^{\circ} \mathrm{E} 131^{\circ} \mathrm{E}$

Wind speed $(\mathrm{m} / \mathrm{s})$

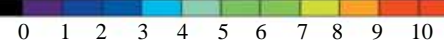

12LST June 5
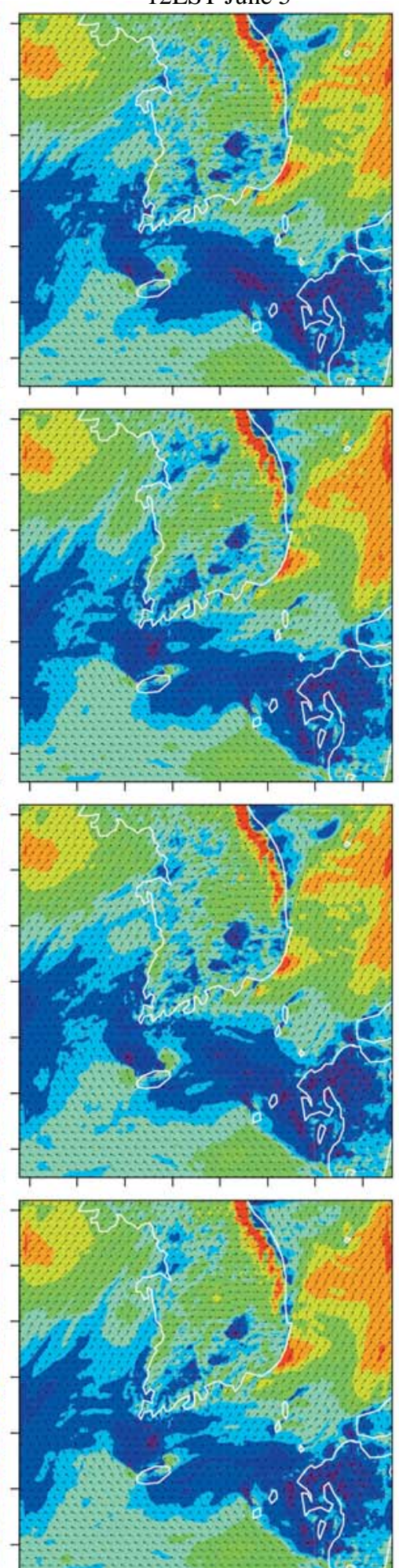

$124^{\circ} \mathrm{E} 125^{\circ} \mathrm{E} 126^{\circ} \mathrm{E} 127^{\circ} \mathrm{E} 128^{\circ} \mathrm{E} 129^{\circ} \mathrm{E} 130^{\circ} \mathrm{E} 131^{\circ} \mathrm{E}$

Wind speed $(\mathrm{m} / \mathrm{s})$

$\begin{array}{lllllllllll}0 & 1 & 2 & 3 & 4 & 5 & 6 & 7 & 8 & 9 & 10\end{array}$

Fig. 4. Horizontal wind distribution for OBS-EXP results ((a) NO_DA, (b) PF_DA, (c) RS_DA, and (d) AL_DA). 
12LST June 4

(a)

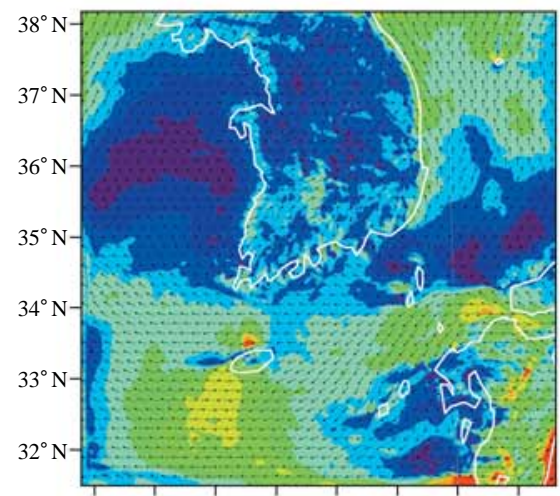

(b)

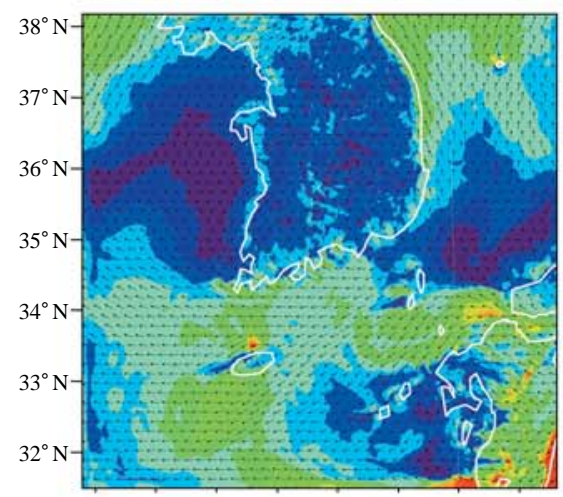

(c)

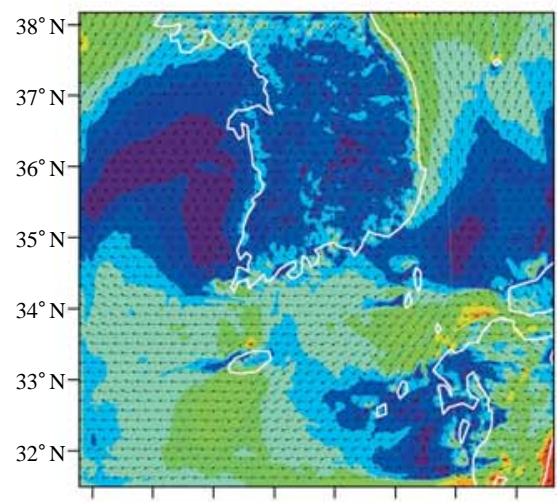

(d)

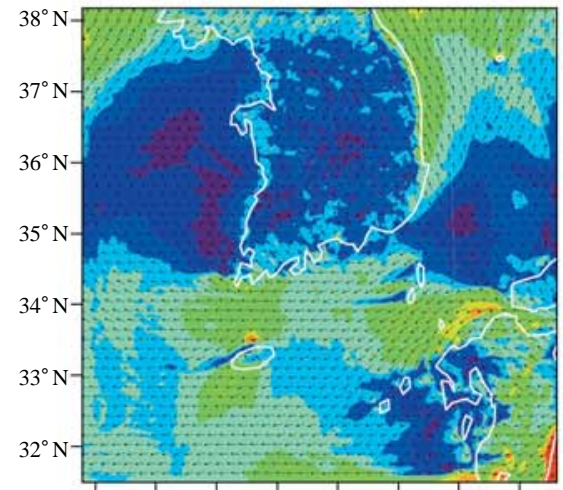

$124^{\circ} \mathrm{E} \quad 125^{\circ} \mathrm{E} 126^{\circ} \mathrm{E} 127^{\circ} \mathrm{E} 128^{\circ} \mathrm{E} 129^{\circ} \mathrm{E} 130^{\circ} \mathrm{E} 131^{\circ} \mathrm{E}$

Wind speed $(\mathrm{m} / \mathrm{s})$

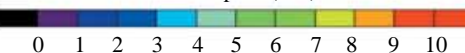

00LST June 5
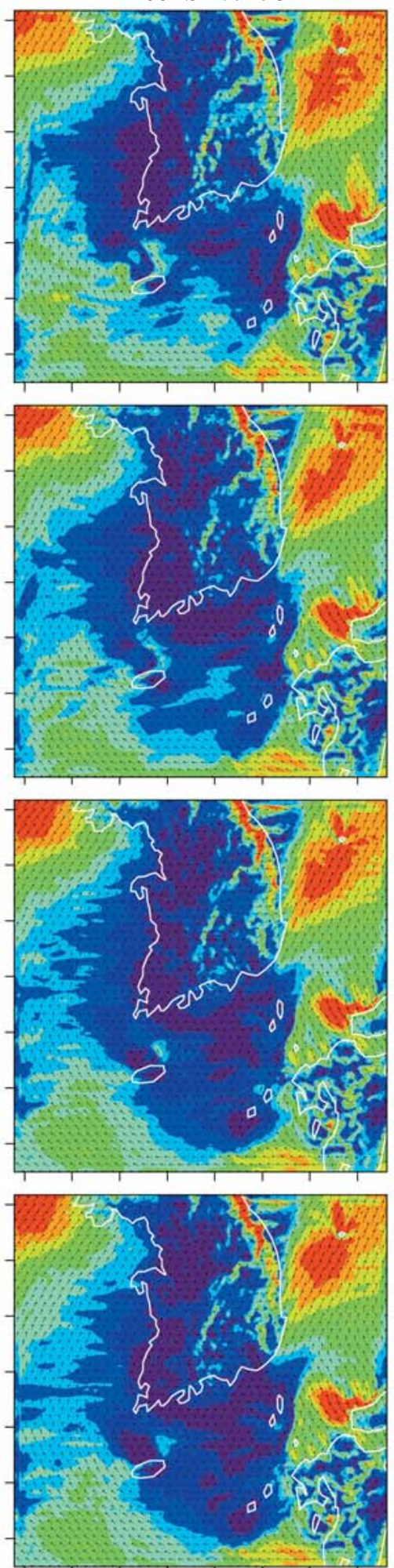

$124^{\circ} \mathrm{E} 125^{\circ} \mathrm{E} 126^{\circ} \mathrm{E} 127^{\circ} \mathrm{E} 128^{\circ} \mathrm{E} 129^{\circ} \mathrm{E} 130^{\circ} \mathrm{E} 131^{\circ} \mathrm{E}$

Wind speed $(\mathrm{m} / \mathrm{s})$

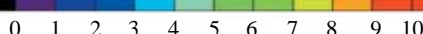

12LST June 5
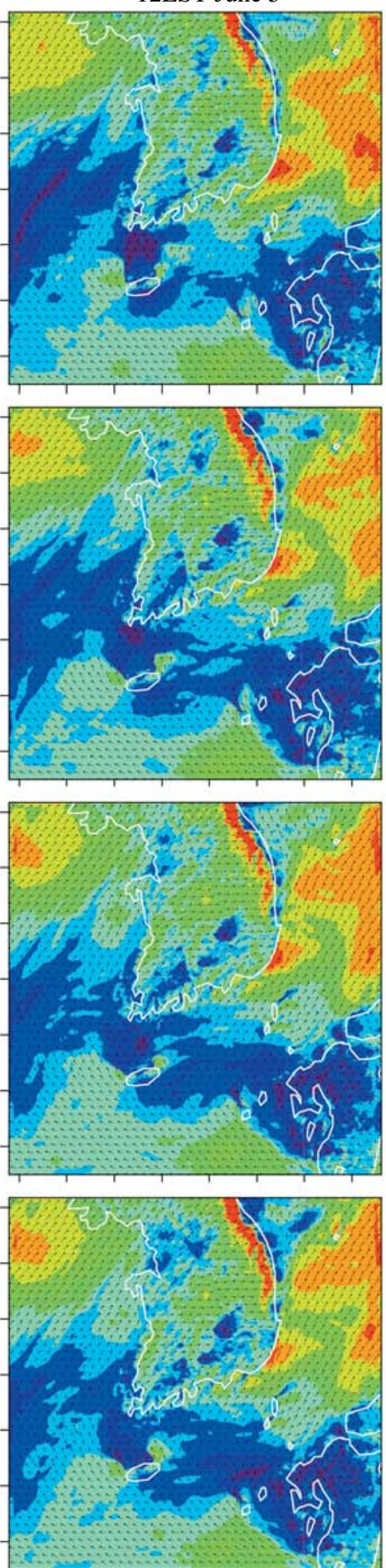

$124^{\circ} \mathrm{E} 125^{\circ} \mathrm{E} \quad 126^{\circ} \mathrm{E} 127^{\circ} \mathrm{E} \quad 128^{\circ} \mathrm{E} \quad 129^{\circ} \mathrm{E} \quad 130^{\circ} \mathrm{E} 131^{\circ} \mathrm{E}$

Wind speed $(\mathrm{m} / \mathrm{s})$

$\begin{array}{lllllllllll}0 & 1 & 2 & 3 & 4 & 5 & 6 & 7 & 8 & 9 & 10\end{array}$

Fig. 5. Same as Fig. 4. but for INT-EXP results ((a) 1h_DA, (b) 3h_DA, (c) 6h_DA, and (d) 12h_DA). 
(a) Haenam

09LST June 4
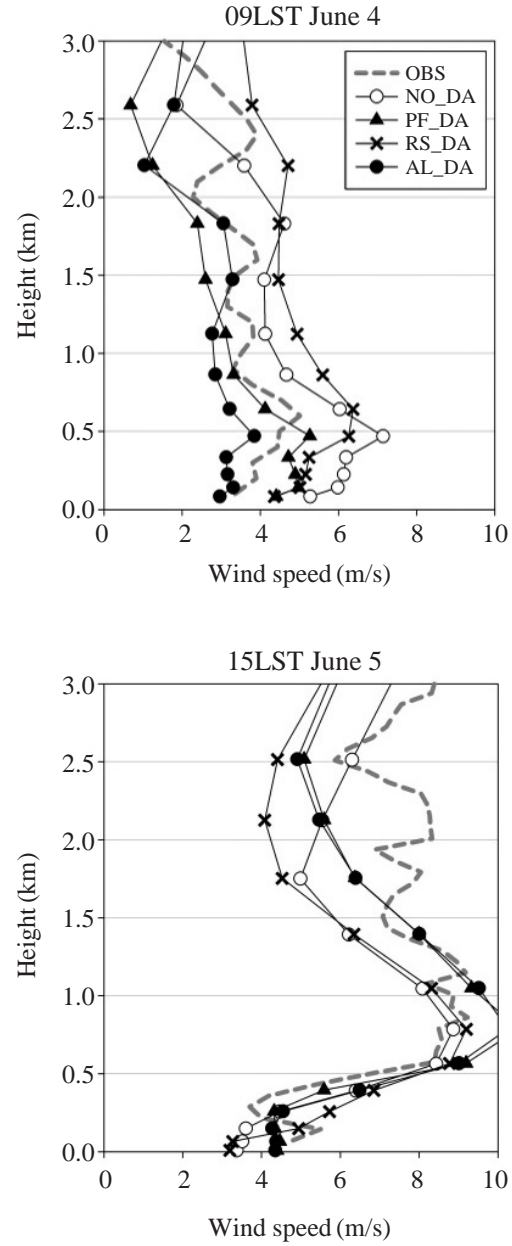

(b) Masan
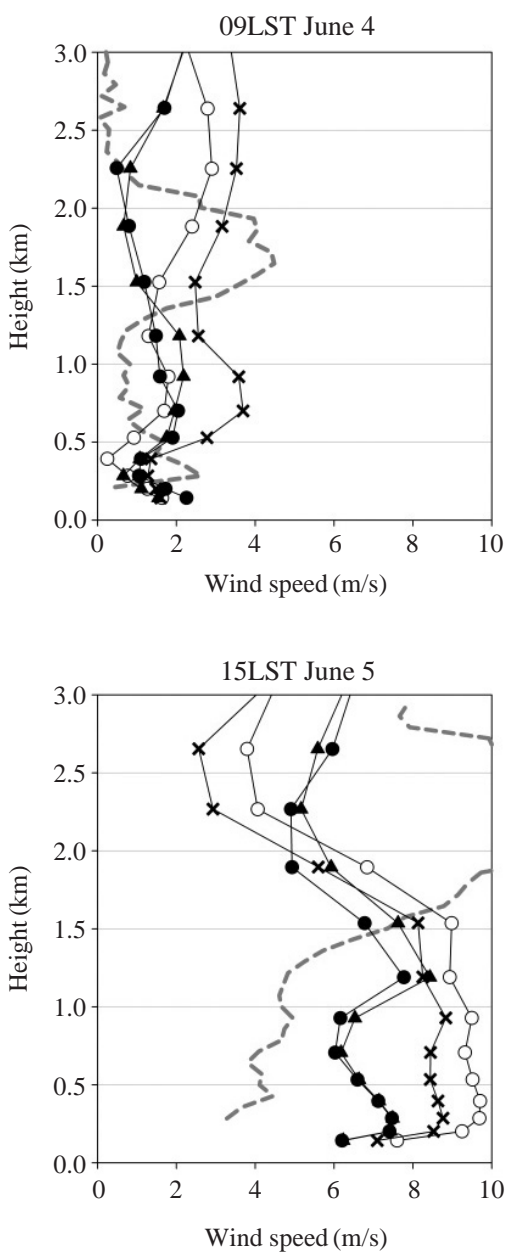

(c) Gwangyang
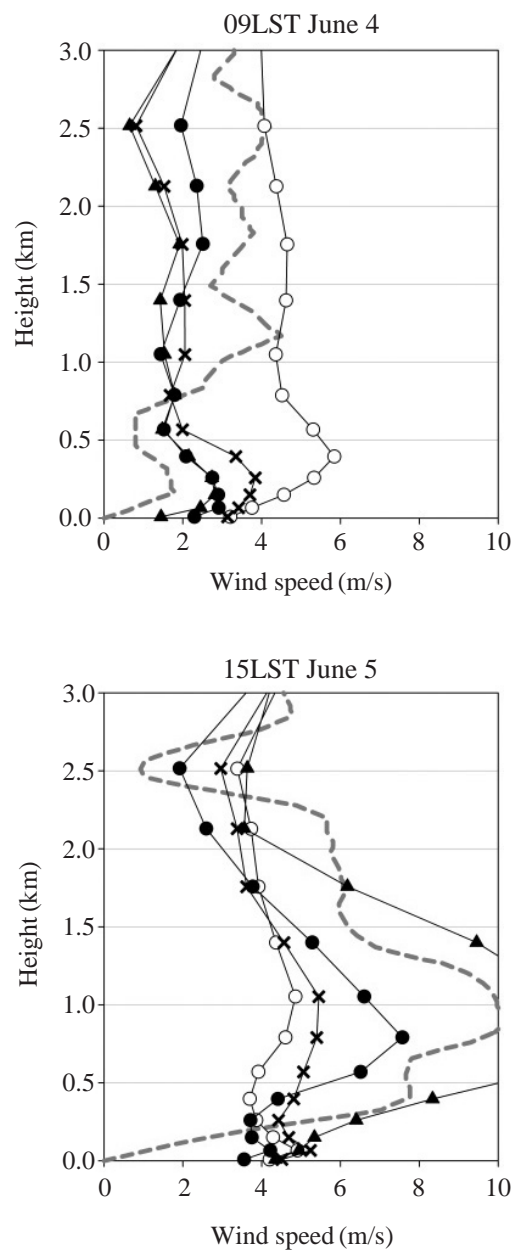

Fig. 6. Calculated (OBS-EXP; solid line) and observed (dashed line) vertical distribution of wind speed ((a) Haenam, (b) Masan, and (c) Gwangyang).

resolution, the changes in wind direction were more complex than the distribution of the wind velocity observed by the sonde. The results of the model did not simulate this rapidly changing wind speed, but the overall pattern was simulated accurately. In most results, AL_DA and PF_DA were similar to the observation profile. In lower level Haenam, wind speeds of $<2 \mathrm{~ms}^{-1}$ were observed at 09 LST on June 4 , but the NO_DA wind speed was considerably overestimated at $6 \mathrm{~ms}^{-1}$. AL_DA estimated approximately $3 \mathrm{~ms}^{-1}$, and when PF_DA was compared to RS_DA, PF_DA showed better results. In lower level Masan, the strong wind at $4 \mathrm{~ms}^{-1}$ was accurately simulated in PF_DA at 15 LST, June 5, and its effectiveness had a significant influence on AL_DA. In the region of Gwangyang, which is located in the middle of Masan and Haenam (Fig. 3), results were greatly affected by profilers in the lower level. This is because the profiler concentra- tion in the lower level meant that the results of AL_DA did not reflect those of RS_DA. Therefore, the profilers had a significant impact on the results for wind distribution in the lower level. This study did not compare the potential temperature and specific humidity with observations. PF_DA shows better results in the simulation of specific humidity than NO_DA, even though the profiler has no data associated with water vapor. This suggests that water vapor advection is affected by the change in the lower level wind, and the degree of simulated specific humidity agrees with the observations.

The results for INT-EXP were compared with vertical observation data (Fig. 7). Comparing the results at profiler sites, better results were found when profiler data were used frequently. Most of the results for all times and all sites agree with the observations of $1 \mathrm{~h}$ _DA except for the overestimation of wind speed that was 
(a) Haenam

09LST June 4
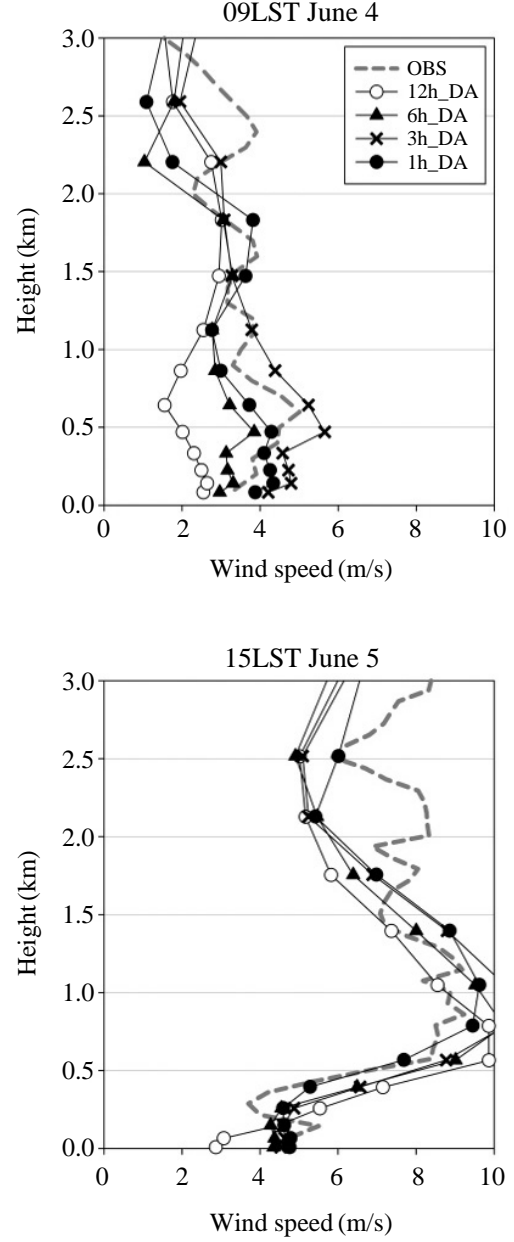

(b) Masan
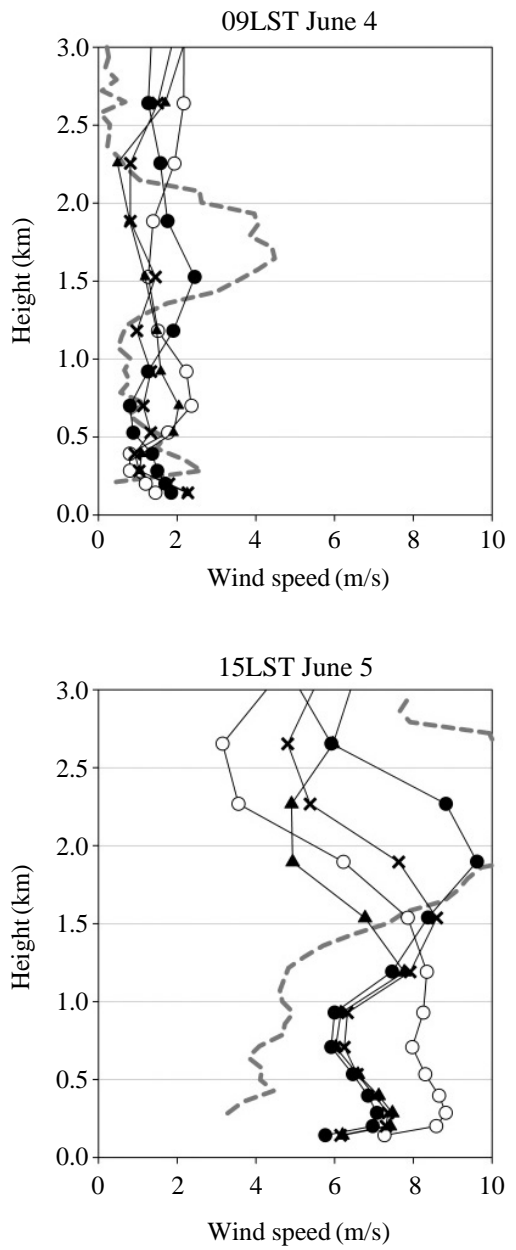

(c) Gwangyang
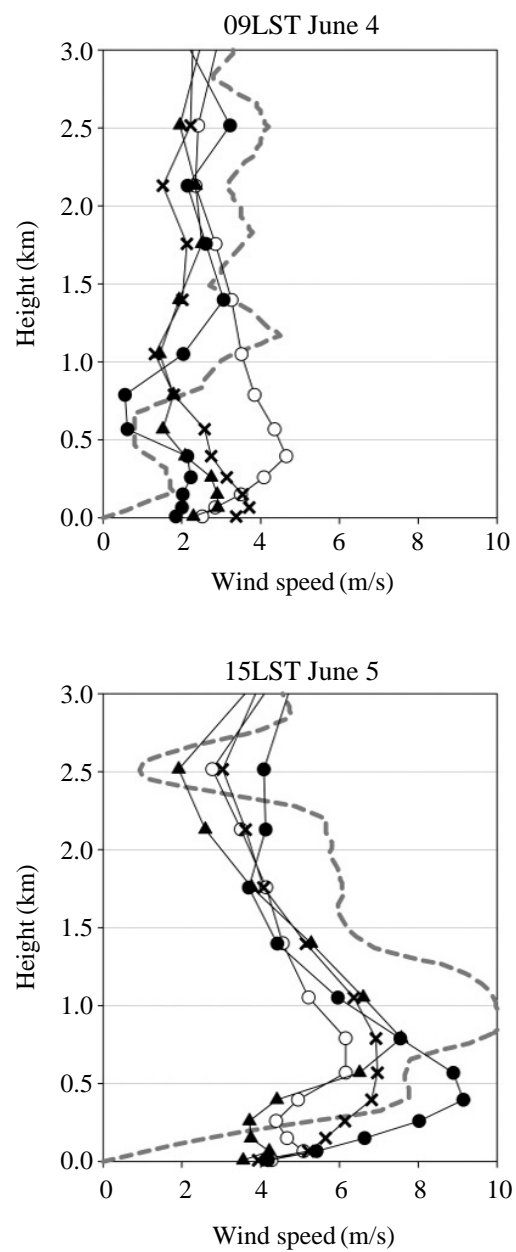

Fig. 7. Same as Fig. 6. but for INT-EXP.

observed at the upper level in Masan at 15 LST, June 5. INT-EXP increased the wind speed at the level where it was underestimated, and reduced it where it was overestimated. The differences in each case were remarkable below the $1 \mathrm{~km}$ level because the profiler produced detailed wind information in the lower layer. The effect of the time interval is not observed when simulating the strong wind speed at the lower levels on June 5. A comparison of the INT-EXP results with the sonde in Gwangyang, which was not used in data assimilation (Fig. 7(c)), revealed the results to be affected by two profiler sites, Haenam and Masan. A slow wind speed due to a weak synoptic effect at 09 LST, June 4 was accurately simulated in 1h_DA, and a high wind speed of $8 \mathrm{~ms}^{-1}$ on the night of June 5 with a strong synoptic effect also agreed with observations. 1h_DA showed the best results not only for wind speed but also for specific humidity (not shown).

\section{3 Comparison with Ground AWS Data}

The diurnal variations in wind speed between model results and site observations where data assimilation was conducted on June 4 and 5 were compared (Fig. 8). The diurnal variations, which were strong winds during the day and weak winds at night, and the wind speeds on June 5 were stronger than those on June 4. Masan (a) and Gwangju (b) in Fig. 8, which are the results from OBS-EXP, show that the surface wind speed decreased at night because the atmosphere became stable. The overestimation of wind speed at dawn by NO_DA at (a) Masan decreased significantly with data assimilation. The maximum wind speed of $4.6 \mathrm{~ms}^{-1}$ at Gwangju on June 5 was overestimated at approximately $6 \mathrm{~ms}^{-1}$ by NO_DA, but improved to $5.0 \mathrm{~ms}^{-1}$ by AL_DA. In addition, the wind speed variation results of AL_DA were most similar to the observations. The trend in wind speed changes seen in the AL_DA results was similar to that of PF_DA because the 
(a) OBS-EXP, Masan

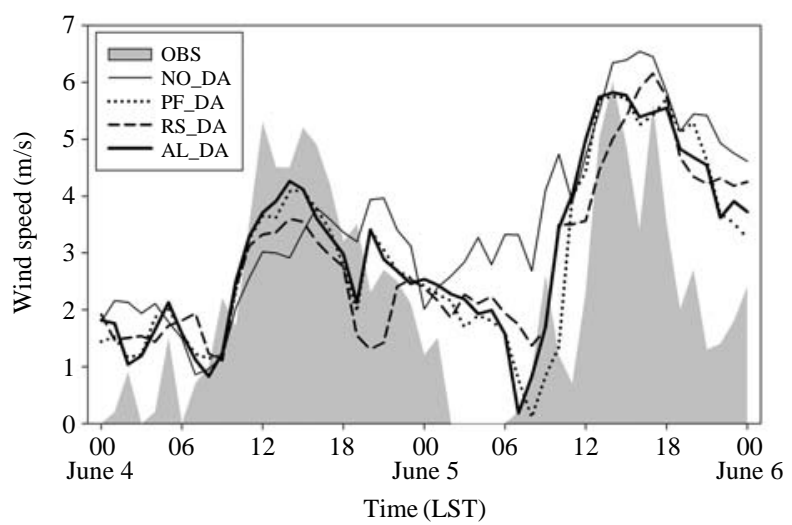

(c) INT-EXP, Haenam

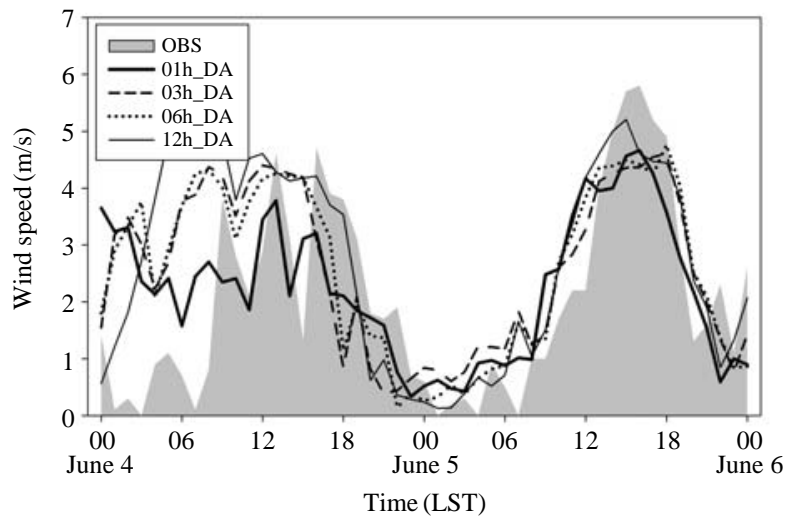

(b) OBS-EXP, Gwangju

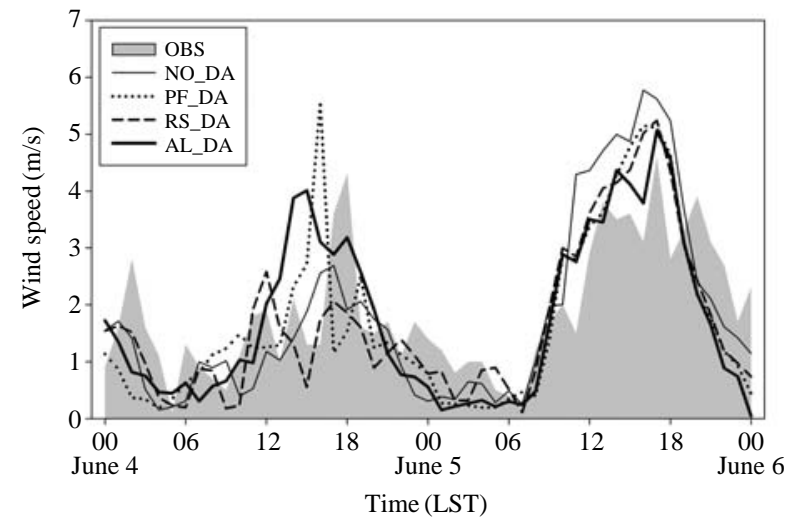

(d) INT-EXP, Gwangju

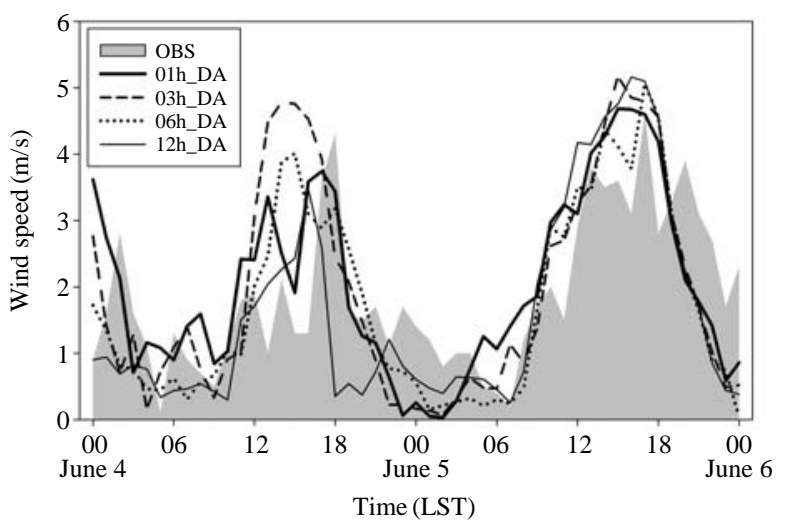

Fig. 8. Calculated and observed (shaded area) time variation of wind speed ((a) OBS-EXP at Masan, (b) OBS-EXP at Gwangju, (c) INT-EXP at Haenam, and (d) INT-EXP at Gwangju).

effect of the profiler data was strongly reflected in the AL_DA results, particularly in comparison with the AWS ground data.

The INT-EXP results (Fig. 8(c), (d)) were significantly affected by the impact of synoptic forcing. The sensitivity of data assimilation with the time interval was much greater on June 4 when synoptic forcing was weak. The daytime wind speed in Haenam was similar to an observation near the 01h_DA, and the wind changes were consistent with observations. There was little difference in 03h_DA and 06h_DA for the slow wind speed at Haenam observed in the early morning, but the wind speed decreased greatly for 01h_DA. In addition, the wind speed variation during the day was accurately simulated by $01 \mathrm{~h} \_$DA. Frequent data assimilation improved the wind speed results during the day and night in Masan. In particular, the sensitivity to the time interval was much better in Gwangju. On the other hand, the results of experiments on June 5 show that the differences in wind speed and diurnal variation with each time interval were reduced relative to those on June 4. The sensitivities on June 4 and 5 for INT-EXP were distinct because the synoptic effect was different. On June 4, when synoptic forcing was weak, local flow occurred at each observation point, and the wind direction and wind speed changes were observed as functions of time. This atmospheric phenomenon can be observed using a profiler with high time resolution, and the results of 03h_DA and 01h_DA, which reflected these benefits, were greatly improved and showed large differences for each case of INT-EXP. On June 5, which had a strong synoptic effect, there were no significant changes in the profiler observations because the winds exhibited little diurnal variation. Therefore, the sensitivity dependence on the time interval was insignificant.

According to wind energy forecasting and an assessment using improved wind fields in the boundary layer, this study focused on the results of wind speed simulations because wind direction does not seriously affect wind power. The simulated results for wind direction were compared with ground observations to determine 
(a) OBS-EXP, Masan

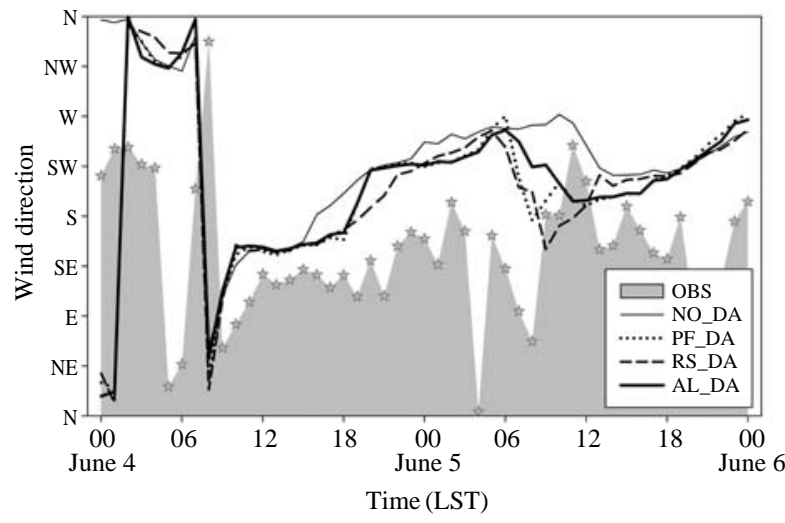

(b) OBS-EXP, Gwangju

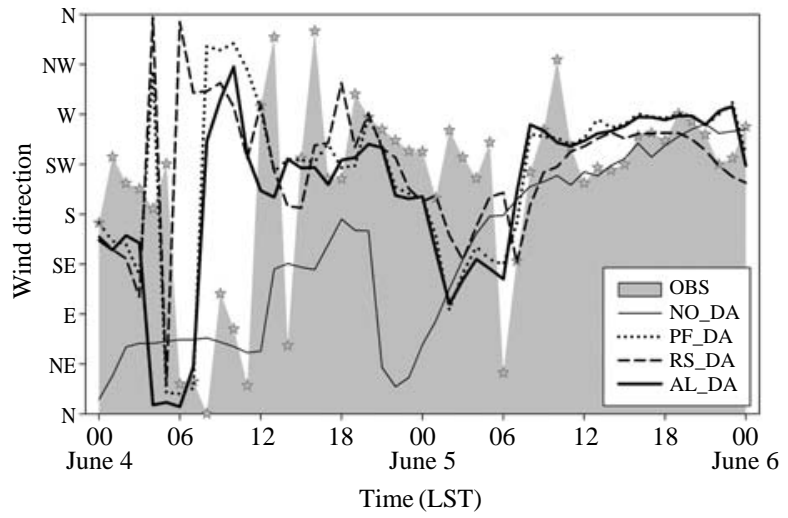

(d) INT-EXP, Gwangju

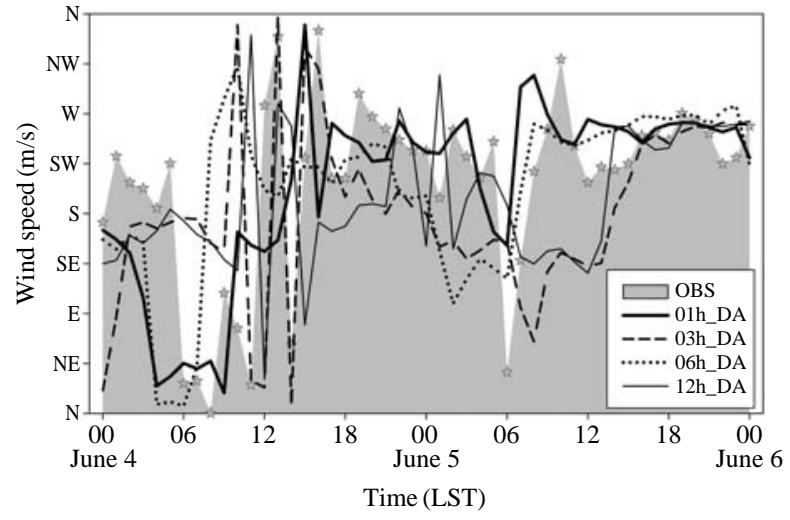

Time (LST) (c) INT-EXP, Haenam

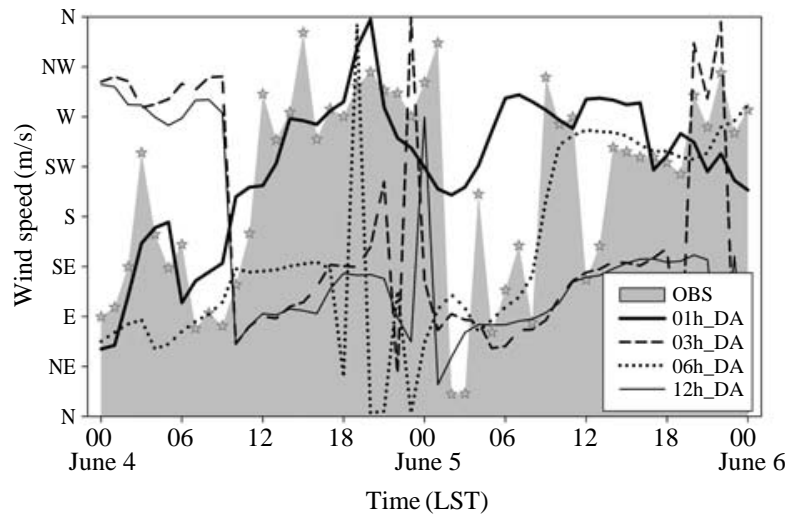

Fig. 9. Same as Fig. 8. but for wind direction.

whether the changes in wind direction due to local circulation were reflected accurately. Fig. 9 compares the results of each experiment and the wind directions determined through ground-based observatories on June 4 and 5 . The direction of the land-sea breeze circulation on June 4 was slightly different due to the different shape of the coastline at each point, but apparent local circulation and changes in wind direction occurred. Variation in wind direction, which was affected by the impact of synoptic wind on the night of June 4 , did not occur. The wind direction at Masan changed from north and northeast before sunrise to a southeast sea breeze during the day, and a southwest sea breeze occurred in Gwang-ju. In Haenam, the night easterly wind also changed to a westerly breeze during the day in the southwest coast of Haenam, and the land-sea breeze cycle was observed by the wind direction changes. The wind direction results of each experiment differed depending on the regions and experiments. In the results of Masan for NO_DA in OBS-EXP, significant improvements were not observed because the results were similar to the observations showing the local circulation on June 4 and the southwesterly synoptic wind on June 5. In Gwangju, the results of the OBS-EXP southwest winds that occurred in NO_DA during the day of June 4 exhibited an easterly wind. However, data assimilation was carried out for southwest winds and the simulated results, which changed over time, were -simulated accurately in the southwesterly direction. In the case of the numerical simulation with a $3 \mathrm{~km}$ horizontal resolution, the representations of the terrain and coastline were presented smoothly, which make it easy to represent the complex flow of the actual terrain without data assimilation. The simulated results under low resolution, however, increased when assimilating the observation data, which thereby detected the complex atmospheric flow. In particular, the differences in experimental results were greater for June 5 than for June 4 because of the synoptic effect. The results of AL_DA were similar to those of PF_DA because the addition of profiler data had a significant effect on ground outcomes. The reception rates of the profiler data in Haenam at low levels were higher than in other regions. Therefore, the re- 
Table 3. Performance statistics of modeled result.

\begin{tabular}{lcc}
\hline \multicolumn{1}{c}{ Description } & Variables & Statistic definition* \\
\hline Mean obs. & $\bar{O}$ & $(1 / N) \sum_{1}^{N} C_{o}$ \\
Mean model & $\bar{M}$ & $(1 / N) \sum_{1}^{N} C_{m}$ \\
Mean bias & MB & $(1 / N) \sum_{1}^{N}\left(C_{m}-C_{o}\right)$ \\
Normalized mean bias & NMB $(\%)$ & $(1 / N) \sum_{1}^{N}\left(C_{m}-C_{o}\right) / \bar{O} \times 100 \%$ \\
Mean error & ME & $(1 / N) \sum_{1}^{N}\left|C_{m}-C_{o}\right|$ \\
Normalized mean error & NME $(\%)$ & $(1 / N) \sum_{1}^{N}\left|C_{m}-C_{o}\right| / \bar{O} \times 100 \%$ \\
Root mean square error & RMSE & $\sqrt{(1 / N) \sum_{1}^{N}\left(C_{m}-C_{o}\right)^{2}}$ \\
Index of agreement & IOA & $(1 / N) \sum_{1}^{N}\left(C_{m}-\bar{M}\right)+\left(C_{o}-\bar{O}\right) / \sigma_{m} \sigma_{o}$ \\
\hline
\end{tabular}

$* \mathrm{~m}=$ modelled, $\mathrm{o}=$ observed.

Table 4. Statistics of surface wind speed for OBS-EXP.

\begin{tabular}{lcrrrr}
\hline & No_DA & PF_DA & RS_DA & AL_DA & obs \\
\hline Mean & 2.95 & 2.60 & 2.63 & $\mathbf{2 . 5 8}$ & 1.96 \\
MB & 0.99 & 0.64 & 0.67 & $\mathbf{0 . 6 3}$ & \\
NMB & 50.67 & 32.81 & 34.12 & $\mathbf{3 1 . 9 5}$ & \\
Me & 1.40 & 1.20 & 1.26 & $\mathbf{1 . 1 9}$ & \\
NME & 71.42 & 61.37 & 64.39 & $\mathbf{6 1 . 0 4}$ & \\
RMSE & 1.82 & 1.58 & 1.65 & $\mathbf{1 . 5 6}$ & \\
IOA & 0.70 & 0.74 & 0.72 & $\mathbf{0 . 7 5}$ & \\
CORR & 0.56 & 0.60 & 0.59 & $\mathbf{0 . 6 0}$ & \\
\hline
\end{tabular}

sults of 01h_DA in INT-EXP showed very good correlations with observations, and land-sea breeze circulations on June 4 were simulated accurately.

\section{4 Statistical Analysis}

The results in previous chapter were qualitatively analyzed by comparing the results of OBS-EXP and INT-EXP with vertical observation data and ground AWS data. This chapter quantitatively analyzes the results of each experiment using the statistical indices listed in Table 3.

The statistics for wind speed for observations at the 33 AWS points and the results of data assimilation were calculated. Table 4 summarizes the results of OBS-EXP. In all cases, OBS-EXP overestimated the mean wind speed and demonstrated a positive MB. In the case of AL_DA, the results of the wind simulation were improved for all statistics. In particular, the normalized mean error (NME) normalized by the average observed wind speed was $71 \%$ of the average wind speed in NO_DA but $61.04 \%$ in AL_DA, showing an approximate $10 \%$ decrease in error. The error reduction in AL_DA with the addition of profiler data was greater in PF_DA (61.37\%) than in RS_DA (64.39\%). In all other figures, the results of PF_DA were better than RS_DA because the wind information of the profiler was detailed in the low levels. This advantage was confirmed by a comparison with the ground AWS.

As the sensitivities on June 4 and 5 were different, the INT-EXP results were calculated statistically by dividing the weak and strong synoptic days. Table 5 shows the results of June 4 and 5 on the left and right, respectively. The results of $01 \mathrm{~h} \_D A$ were the best on the weak synoptic days. They still showed a positive bias, but in the 01h_DA results the mean wind speed decreased from $2.56 \mathrm{~ms}^{-1}$ to $1.99 \mathrm{~ms}^{-1}$, which is similar to observed values. Overall, the normalized mean error (NME) of the average wind speed during the day showed the greatest decrease of $28 \%$. Therefore, the more frequently the profiler data were used, the more the simulation results were enhanced under weak synoptic conditions. The statistics on the strong synoptic days (Table 5, right) showed that the simulations provided better results at all time intervals than NO_DA, 
Table 5. Statistics of surface wind speed results on the condition of weak synoptic (left) and strong synoptic (right) for INT-EXP.

\begin{tabular}{|c|c|c|c|c|c|c|c|c|c|c|c|c|}
\hline & \multicolumn{6}{|c|}{ June 4} & \multicolumn{6}{|c|}{ June 5} \\
\hline & No_DA & 1h_DA & 3h_DA & 6h_DA & 12h_DA & obs & No_DA & 1h_DA & 3h_DA & 6h_DA & 12h_DA & obs \\
\hline Mean & 2.56 & 1.99 & 2.12 & 2.19 & 2.44 & 1.53 & 3.57 & 3.04 & 3.02 & 3.01 & 3.17 & 2.38 \\
\hline MB & 1.23 & 0.65 & 0.84 & 0.87 & 1.07 & & 1.17 & 0.82 & 0.76 & 0.69 & 0.85 & \\
\hline NMB & 80.16 & 42.37 & 54.79 & 56.58 & 69.50 & & 49.31 & 34.59 & 31.73 & 28.78 & 35.82 & \\
\hline $\mathrm{Me}$ & 1.47 & 1.04 & 1.14 & 1.22 & 1.41 & & 1.76 & 1.45 & 1.42 & 1.32 & 1.37 & \\
\hline NME & 95.72 & 67.71 & 74.31 & 79.52 & 92.03 & & 73.89 & 60.79 & 59.62 & 55.24 & 57.61 & \\
\hline RMSE & 1.90 & 1.33 & 1.55 & 1.66 & 1.89 & & 1.95 & 1.69 & 1.66 & 1.62 & 1.71 & \\
\hline IOA & 0.69 & 0.82 & 0.77 & 0.77 & 0.71 & & 0.73 & 0.80 & 0.83 & 0.82 & 0.81 & \\
\hline CORR & 0.42 & 0.67 & 0.60 & 0.61 & 0.51 & & 0.57 & 0.60 & 0.60 & 0.60 & 0.58 & \\
\hline
\end{tabular}

but did not show a significant effect on the results of 03h_DA or 01h_DA. The 06h_DA showed low or similar errors in all statistics except for the IOA and CORR. The differences between 06h_DA and 12h_DA led to a definite effect, but the use of data assimilation for intervals shorter than six hours had little or no effect. As explained earlier in the time series analysis, the profiler data did not affect the dominant wind direction and wind speed under strong synoptic conditions. The diurnal variations of the statistics averaged by space differed significantly according to the time intervals of data assimilation due to the synoptic effect (Fig. 9). The errors for 01h_DA during the day of June 4 were the lowest and highest in RMSE and IOA, respectively. However, the sensitivity of the time interval was reduced for the night of June 4, and the results from June 5 were not different between experiments.

\section{SUMMARY AND CONCLUSIONS}

In this study, observation data that were put through three-dimensional variational data assimilation were used to enhance the ability to simulate atmospheric phenomena near complex coastal areas. The effects of synoptic forcing were also analyzed. The data used in the data assimilation were profiler data with excellent vertical and time resolutions. It was possible to simulate the wind at complex coastal areas using data from Kunsan, Haenam, and Masan, which are coastal areas adjacent to the southwest coast of Korea. An Observing System Experiment (OBS-EXP) was performed to examine the effect of 3DVAR using the profiler data, and a data assimilation interval experiment (INT-EXP) was performed to investigate the advantages of the time resolution.

A comparison of the horizontal distributions of the wind revealed that the two experiments produced similar wind directions but different wind speeds. In particular, differences in wind speed distributions between the inland and coastal areas were observed using vertical observational data. These results were compared with vertical observations and ground AWS data to qualitatively analyze the results of the two tests. The results were closer to observations when the OBSEXP results were analyzed at the site of data assimilation. AL_DA showed the best ability to predict the vertical wind speed distribution. INT-EXP with frequent time intervals was similar to observations, particularly at the profiler site. A comparison with sonde observations at Gwangyang, which were not used for data assimilation, showed that the simulations using all data and hourly data assimilation were closest to observations because Gwangyang is located between the two profiler sites. The time series for wind speed at ground AWS was well-simulated using data assimilations for the slower wind speeds at night and the overall wind speed change with time. INT-EXP in the weak synoptic day showed significant differences in each case, but was not sensitive to the time interval on the strong synoptic day.

We conducted an analysis of the statistics for the quantitative evaluation of the two experiments. Although the statistical analysis comparing the results of OBS-EXP with AWS on the ground had a positive bias, for AL_DA using all of the data we observed an excellent ability to assimilate all statistical values. In particular, PF_DA using only the profiler was better than RS_DA using only the sonde. Therefore, the effect of the observed data using the profiler below the atmospheric boundary layer is greater than when using the sonde. The results of INT-EXP on a weak synoptic day showed good results with more detailed time intervals, but on a strong synoptic day showed the same results except for the 12-hour intervals and good results with 6-hour intervals. Because the change in wind direction in the lower level reflected the wind profiler data, shorter time intervals showed better results on weak synoptic days. However, the results were not better on strong synoptic days.

These results highlight the importance of using profiler data when simulating atmospheric phenomena 
below the boundary layer. The use of observation data during variational data assimilation was suggested, and the characteristics of the assimilation depended on the synoptic effect. This information is expected to improve numerical models that simulate conditions below the atmospheric boundary layer. The use of three-dimensional data assimilation produces good results from many observations. The inclusion of radar and satellite remote sensing data will further improve the performance of the numerical model. In addition, it is important to review the scientific quality control process in order to allow data assimilation using high quality observational data.

\section{ACKNOWLEDGEMENTS}

This work was funded by the Korea Meteorological Administration Research and Development Program under Grant CATER 2006-2205.

\section{REFERENCES}

Atlas, R. (1997) Atmospheric Observations and Experiments to Assess Their Usefulness. Journal of the Meteorological Society of Japan 75, 111-130.

Barker, D.M., Huang, W., Guo, Y.-R., Bourgeois, A., Xiao, X.N. (2004) A three-dimensional variational data assimilation system for MM5: Implementation and initial results, Monthly Weather Review 132, 897-914.

Benjamin, S.G., Schwartz, B.E., Szoke, E.J., Koch, S.E. (2004) The value of wind profiler data in U.S. weather forecasting, Bulletin of the American Meteorological Society 85(12), 1871-1886.

Hirschberg, P.A., Shafran, P.C., Elsberry, R.L., Ritchie, E.A. (2001) An observing system experiment with the West Coast Picket Fence, Monthly Weather Review 129, 2585-2599.

Ide, K., Courtier, P., Ghil, M., Lorenc, A.C. (1997) Unified notation for data assimilation: Operational, sequential and variational, Journal of the Meteorological Society of Japan 75, 181-189.

Ishihara, M., Kato, Y., Abo, T., Kobayashi, K., Izumikawa, Y. (2006) Characteristics and performance of the operational wind profiler network of the Japan Meteorological Agency, Journal of the Meteorological Society of Japan 84(6), 1085-1096.

Kim, H.-G., Jang, M.-S., Kyong, N.-Ho., Lee, H.W., Choi,
H.-J., Kim, D.-H. (2006) Establishment of the low-resolution national wind map by numerical wind simulation, Journal of the Korean Solar Energy Society 26(4) 31-38. (in Korean)

Lee, H.W., Won, H.Y., Choi, H.-J. (2004) Numerical simulation of atmospheric flow fields using surface observational data in the complex coastal regions, Journal of Korean Society for Atmospheric Environment 20(5), 633-645. (in Korean)

Lee, H.W., Kim, M.-J., Kim, D.-H., Kim, H.-G., Lee, S.-H. (2009a) Investigation of the assimilated surface wind characteristics for the evaluation of wind resources, Journal of Korean Society for Atmospheric Environment 25(1), 1-14. (in Korean)

Lee, H.W., Park, S.-Y., Lee, S.-H., Lim, H.-H. (2009b) Characteristics of ozone advection in vertical observation analysis around complex coastal area, Journal of Korean Society for Atmospheric Environment 25(1), 57-74. (in Korean)

Lee, S.H., Kim, Y.K., Kim, H.S., Lee, H.W. (2007) Influence of dense surface meteorological data assimilation on the prediction accuracy of ozone pollution in the southeastern coastal area of the Korean Peninsula, Atmospheric Environment 41, 4451-4465.

Mike Fisher (2001) Assimilation technique (3): 3dvar, ECMWF, Meteorological Training Course Lecture Series.

National Institute Meteorological Research (2003) Korea Enhanced Observing Period (KEOP) 3, 25-45.

National Center for Atmospheric Research (2008) Weather Research \& Forecasting: ARW Version 3 Modelling System User's Guide.

Park, O.-R., Kim, Y.-S., Cho, C.-H. (2005) The observing system experiments with the wind profiler and autosonde at Haenam, Asia-Pacific Journal of Atmospheric Sciences 41(1), 57-71. (in Korean)

Skamarock, W.C., Klemp, J.B., Dudhia, J., Gill, D.O., Barker, D.M., Duda, M.G., Huang, X.Y., Wang, W., Powers, J.G. (2008) A Description of the Advanced Research WRF Version 3, Ncar Technical Note, NCAR/ TN-475+STR.

University Corporation for Atmospheric Research (2001) Understanding Data Assimilation: How Models Create Their Initial Conditions, www.meted.ucar.edu.

Won, H.Y., Park, C.-G., Kim, Y.-H., Lee, H.-S., Cho, C.-H. (2008) Observing system experiments using the intensive observation data during KEOP-2005, Atmosphere 18(4), 299-316. (in Korean)

(Received 12 January 2010, accepted 15 November 2010) 